\title{
Nimesulide, a selective COX-2 inhibitor, acts synergistically with ionizing radiation against A549 human lung cancer cells through the activation of caspase- 8 and caspase-3
}

\author{
BYEONG MO KIM ${ }^{1}$, JUYOON WON ${ }^{1}$, KYUNG AH MAENG ${ }^{1}$, YOUNG SOO HAN ${ }^{1}$, \\ YEON-SOOK YUN ${ }^{1}$ and SUNG HEE HONG ${ }^{1}$ \\ ${ }^{1}$ Division of Radiation Cancer Research, Korea Institute of Radiological \& Medical Sciences, \\ 215-4 Gongneung-Dong, Nowon-Gu, Seoul 139-706, Korea
}

Received December 29, 2008; Accepted February 25, 2009

DOI: 10.3892/ijo_00000276

\begin{abstract}
Several lines of evidence suggest that non-steroidal anti-inflammatory drugs (NSAIDs) have a radiosensitizing effect on cancer cells in vitro and in vivo, but little is known about the underlying cellular mechanism. In this study, we found that the treatment with the NSAID nimesulide significantly increased the sensitivity of A549 human non-small cell lung cancer cells to radiotherapy. The combined nimesulideradiation treatment increased apoptosis, induced the cleavage of caspase-3, caspase-9, and poly(ADP-ribose) polymerase (PARP), activated caspase- 8 , and induced cleavage of Bid. A pan-caspase inhibitor, z-VAD-fmk, suppressed this increase in apoptosis and also suppressed the cleavage of caspase-8, caspase-3, and PARP, suggesting a caspase-dependent mechanism. In addition, z-IETD-fmk, a selective caspase- 8 inhibitor, suppressed the nimesulide- and radiation-induced cleavage activation of caspase- 9 , caspase- 3 , caspase- 8 , and Bid, and suppressed the concomitant apoptosis, indicating that the nimesulide-induced increase in radiosensitivity was initiated by caspase- 8 . However, the caspase- 3 inhibitor z-DEVD-fmk failed to suppress activation of the caspase-8/Bid pathway, indicating that caspase- 3 activation occurred downstream of caspase- 8 activation in our experiments. Marked antitumor effects, which were evaluated by measuring protracted tumor regression, were observed when nude mice were treated with a combination of nimesulide at a clinically achievable dose $(0.5 \mathrm{mg} / \mathrm{kg})$ and radiation therapy. Our results, demonstrating the radiosensitivity-increasing and tumor growth-inhibiting effects of nimesulide, suggest that nimesulide may be suitable as an adjuvant to enhance the efficacy and selectivity of radiotherapy.
\end{abstract}

Correspondence to: Dr Sung Hee Hong, Division of Radiation Cancer Research, Korea Institute of Radiological \& Medical Sciences, 215-4 Gongneung-Dong, Nowon-Gu, Seoul 139-706, Korea E-mail: gobrian@kcch.re.kr

Key words: radiation, nimesulide, COX-2 inhibitor, caspase-8, caspase-3

\section{Introduction}

Although radiotherapy is important in the treatment of non-small cell lung cancer, very few malignancies have been cured using single modalities of radiotherapy. Therefore, molecules that can target specific pathophysiological or molecular pathways have been investigated for use as radiation sensitizers. For example, cyclooxygenase (COX)-2 inhibitors have been shown to enhance the radioresponse of cultured human cancer cell lines and immunodeficient mice $(1,2)$. However, little is known about the molecular and biochemical mechanisms by which COX-2-selective non-steroidal antiinflammatory drugs (NSAIDs) enhance the radioresponse of tumor cells. In some types of cancer, radiation is thought to work by inducing apoptosis, and effective anticancer radiotherapy is frequently associated with increased levels of apoptosis markers in vitro and in vivo.

Activation of the apoptosis-related cysteine proteases known as caspases plays a central role in the induction of apoptosis. There are two main pathways of apoptotic signaling: the 'intrinsic' mitochondria-mediated pathway and the 'extrinsic' death-receptor-induced pathway (3). The intrinsic pathway is initially mediated by disruption of the mitochondrial membrane potential and cytochrome c release from the mitochondria, leading to caspase- 9 activation and then caspase- 3 activation $(4,5)$. In contrast, the extrinsic apoptotic pathway is triggered by extracellular signaling through transmembrane death receptors, such as Fas, TNF, and TRAIL, and involves the activation of caspase- 8 and/or caspase-10 (6-8). Activated caspase- 8 cleaves Bid, which then translocates from the cytosol to the mitochondria, where it mediates cytochrome $\mathrm{c}$ release and thus bridges the extrinsic and intrinsic apoptotic pathways (9).

Nimesulide (N-4-nitro-2-phenoxyphenyl-methanesulfonamide), a selective COX-2 inhibitor, is a drug with antiinflammatory, anti-pyretic, and analgesic properties $(10,11)$. It specifically inhibits the inducible form of COX, COX-2, rather than the constitutive form, COX-1 (12), and is well tolerated by adult, elderly, and pediatric patients (10). It also has chemopreventive activity against colon, liver, breast, tongue, and urinary bladder carcinogenesis (13-17). Grimes et al previously suggested the possibility that nimesulide 
might be used as a radiosensitizer in the treatment of non-small cell lung cancer (18). However, the apoptotic characteristics of the combination of radiation and nimesulide remain to be elucidated.

In this study, we investigated the mechanisms underlying the synergistic effect of radiotherapy and nimesulide treatment in the non-small cell lung cancer cell line A549. Our preliminary data indicate that nimesulide is a more effective radiosensitizer than celecoxib (a well-known COX-2 inhibitor) in A549 cells and that the nimesulide-induced radiosensitizing effect is not COX-2 dependent.

\section{Materials and methods}

Reagents. Nimesulide, celecoxib, crystal violet, and propidium iodide were obtained from Sigma (St. Louis, MO, USA). The pan-caspase inhibitor z-VAD-fmk, the selective caspase-8 inhibitor z-IETD-fmk, and the selective caspase-3 inhibitor z-DEVD-fmk were obtained from Calbiochem (La Jolla, CA, USA).

Cell culture and drug treatment. The human non-small cell lung cancer cell line A549 was grown in RPMI-1640 medium (Gibco BRL Life Technologies, Gaithersburg, MD, USA) containing $10 \%$ fetal bovine serum (FBS), $100 \mathrm{U} / \mathrm{ml}$ penicillin, and $100 \mu \mathrm{g} / \mathrm{ml}$ streptomycin (Gibco BRL Life Technologies) at $37^{\circ} \mathrm{C}$ in an atmosphere containing $5 \% \mathrm{CO}_{2}$. Cells were incubated with $200 \mu \mathrm{M}$ nimesulide or $20 \mu \mathrm{M}$ celecoxib for $24 \mathrm{~h}$ before irradiation. In some cases, cells were pretreated for $1 \mathrm{~h}$ with a caspase inhibitor $(50 \mu \mathrm{M} \mathrm{z}$-VAD-fmk, z-IETDfmk, or z-DEVD-fmk) before treatment with nimesulide and radiation.

Clonogenic survival assay. Cells were trypsinized, counted, and plated into $60-\mathrm{mm}$ dishes at a density of 500 cells/dish. Cells were incubated with $200 \mu \mathrm{M}$ nimesulide or $20 \mu \mathrm{M}$ celecoxib for $24 \mathrm{~h}$ and then irradiated with various doses of $\gamma$-radiation at a dose rate of $3.2 \mathrm{~Gy} / \mathrm{min}$ using a Gammacell 3000 (Canada). After 10-14 days of incubation, the dishes were stained with $1 \%$ crystal violet in methanol, and colonies consisting of more than 100 cells were counted. The surviving fraction (SF) was calculated as mean colonies/ (cells inoculated x plating efficiency).

Flow cytometric analysis. Apoptosis was detected by sub-G1 fluorescence-activated cell-sorter (FACS) analysis using a FACScan flow cytometer (Becton-Dickinson, Franklin Lakes, NJ, USA). Cells were harvested, washed with phosphatebuffered saline (PBS), and fixed in $70 \%$ ethanol at $-20^{\circ} \mathrm{C}$. After $24 \mathrm{~h}$, the cells were collected by centrifugation, resuspended in PBS, and digested with $50 \mu \mathrm{g} / \mathrm{ml}$ RNase A. Cells were stained with $50 \mu \mathrm{g} / \mathrm{ml}$ propidium iodide for $30 \mathrm{~min}$ in the dark before analysis by flow cytometry (Becton-Dickinson FACSort). Ten thousand cells were measured per sample, and the analysis was performed using Cell Quest Pro software (Becton-Dickinson).

Caspase activity assay. A FLICE/Caspase-8 Colorimetric assay kit and a Caspase-3/CPP32 Colorimetric assay kit (BioVision, Mountain View, CA, USA) were used to deter- mine the enzymatic activities of caspase- 8 and caspase-3, respectively. Cells lysates were prepared in the lysis buffer provided by the manufacturer. After lysates were normalized for protein content, they were incubated with reaction buffer and labeled substrate at $37^{\circ} \mathrm{C}$ for $2 \mathrm{~h}$. Substrates for caspase- 8 and caspase- 3 activity assays were IETD-p-nitroanilide (IETDpNA) and DEVD-p-nitroanilide (DEVD-pNA), respectively. Caspase activity was measured by spectrophotometric detection of the chromophore pNA at $405 \mathrm{~nm}$ after it was cleaved from the substrate IETD-pNA or DEVD-pNA.

Western blot analysis. Western blots were performed to monitor apoptotic signaling. Cells were washed with PBS and solubilized in lysis buffer (25 mM HEPES, 0.1\% SDS, $0.5 \%$ deoxycholate, $1 \%$ Triton X-100, $10 \mathrm{mM}$ EDTA, $10 \mathrm{mM}$ $\mathrm{NaF}, 125 \mathrm{mM} \mathrm{NaCl})$. The protein was then collected after centrifugation at $13,000 \mathrm{rpm}$ for $10 \mathrm{~min}$ at $4^{\circ} \mathrm{C}$. Aliquots of the resulting supernatant fractions $(20 \mu \mathrm{g} /$ lane $)$ were separated by SDS-PAGE, transferred to polyvinylidene difluoride membranes, and probed with specific antibodies against caspase-8, caspase-9, caspase-3, actin (from Santa Cruz Biotechnology, Santa Cruz, CA, USA), PARP (from BD Bioscience, Pharmingen, Heidelberg, Germany), cleaved caspase-3, or Bid (from Cell Signaling Technology, Danvers, MA, USA). Blots were developed using a peroxidaseconjugated secondary antibody and visualized by chemiluminescence with ECL or ECL-plus (Amersham Biosciences, Little Chalfont, Buckinghamshire, UK).

Tumor growth-delay assay. Flank xenografts were established in 7-week-old female athymic BALB/c nude mice by subcutaneous injection of $1 \times 10^{6}$ A549 cells resuspended in $0.1 \mathrm{ml}$ of PBS. Tumors were allowed to grow for 7 days before treatment. The mice were randomized into four groups (no therapy, nimesulide alone, irradiation alone, nimesulide + irradiation) of five mice each. Tumors were measured with calipers, and tumor volume was calculated as largest diameter $(\mathrm{mm}) \times$ smallest diameter ${ }^{2}\left(\mathrm{~mm}^{2}\right) / 2$. The mean tumor volumes of each group were nearly equal, at $\sim 70-80 \mathrm{~mm}^{3}$.

Nimesulide was solubilized in $10 \%$ dimethyl sulfoxide (DMSO) in PBS, pH 7.4, immediately before each treatment, and nimesulide or vehicle (DMSO) was administered to the mice by intraperitoneal injection at a dose of $0.5 \mathrm{mg} / \mathrm{kg}$. After $24 \mathrm{~h}$, a ${ }^{60} \mathrm{Co}$ irradiator was used to locally administer a single radiation dose of 8 Gy to the flanks bearing the A549 xenografts.

Statistical analyses. Statistical analyses were performed using the SAS 8.1 statistical analysis program for Windows (SAS Institute, Cary, NC). All experiments were repeated three times. The P-values for Fig. 1 were calculated using a paired two-tailed Student's t-test. The P-values for Figs. 2A and C, $3 \mathrm{~A}$, and $5 \mathrm{C}$ were calculated using ANOVA/Dunnett tests. The results are expressed as means \pm SEM, and differences were considered significant at $\mathrm{P}<0.05$.

\section{Results}

Combined nimesulide-radiation treatment enhances the radiation response of $A 549$ lung cancer cells. Celecoxib, a 


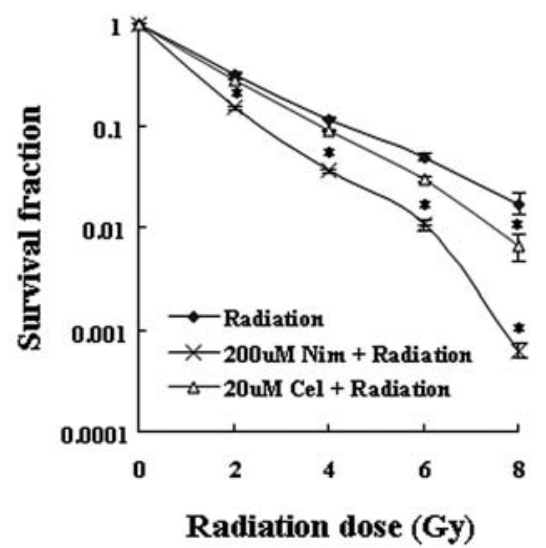

Figure 1. Nimesulide enhances radiosensitivity in A549 cells. Curves indicate the clonogenic survival fraction of A549 cells after irradiation at the indicated doses with or without nimesulide $(200 \mu \mathrm{M})$ or celecoxib $(20 \mu \mathrm{M})$ pretreatment $24 \mathrm{~h}$ before irradiation. Cells were cultured for 12-14 days until colonies were obtained. Survival fractions for the nimesulide-radiation and celecoxibradiation combination treatments were normalized to the cytotoxicity of radiation treatment alone. Data shown represent means \pm SEM of three independent experiments $\left({ }^{*} \mathrm{P}<0.05\right.$ compared to irradiation only; paired two-tailed Student's t-test). $\bullet$ Irradiation only; $\Delta$, irradiation plus $20 \mu \mathrm{M}$ celecoxib; $\mathrm{x}$, irradiation plus $200 \mu \mathrm{M}$ nimesulide.

selective inhibitor of COX-2, is known to increase radiation sensitivity in several animal tumor models, including breast and lung tumors $(19,20)$. However, it does not have a significant radiosensitizing effect on A549 human lung carcinoma cells (19). We examined the radiosensitizing effect of the NSAID nimesulide on these cells.

We pretreated A549 cells with $200 \mu \mathrm{M}$ nimesulide or $20 \mu \mathrm{M}$ celecoxib for $24 \mathrm{~h}$ and then challenged them with various doses of $\gamma$-radiation for an additional $24 \mathrm{~h}$. At the time of irradiation, cells undergoing pretreatment with either nimesulide or celecoxib exhibited identical cell survival rates of about $95 \%$ (data not shown). However, as shown in Fig. 1, clonogenic survival after irradiation was markedly lower after nimesulide pretreatment than after celecoxib pretreatment, indicating that nimesulide is a stronger radiosensitizer than is celecoxib.

Combined treatment with nimesulide and radiation enhances apoptotic cell death of A549 lung cancer cells. To investigate the mechanism of nimesulide-induced radiosensitization in A549 lung cancer cells, we analyzed the subdiploid cellular DNA fraction (sub-G1 DNA content). As shown in Fig. 2A, cell populations exposed to $8 \mathrm{~Gy}$ of radiation alone or to $200 \mu \mathrm{M}$ nimesulide alone exhibited minimal and moderate increases, respectively, in apoptosis, whereas populations exposed to both treatments exhibited a dramatic increase in apoptosis.

Activation of a caspase cascade leading to PARP cleavage by combined nimesulide-radiation treatment. To evaluate the precise apoptotic mechanism induced by combined
A.

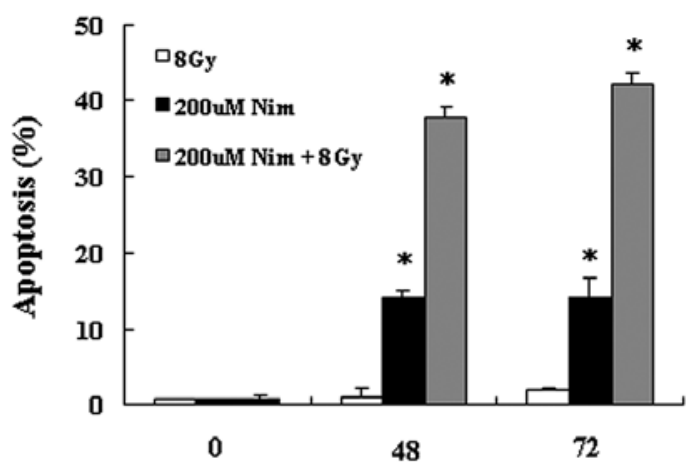

Time (h)
B.

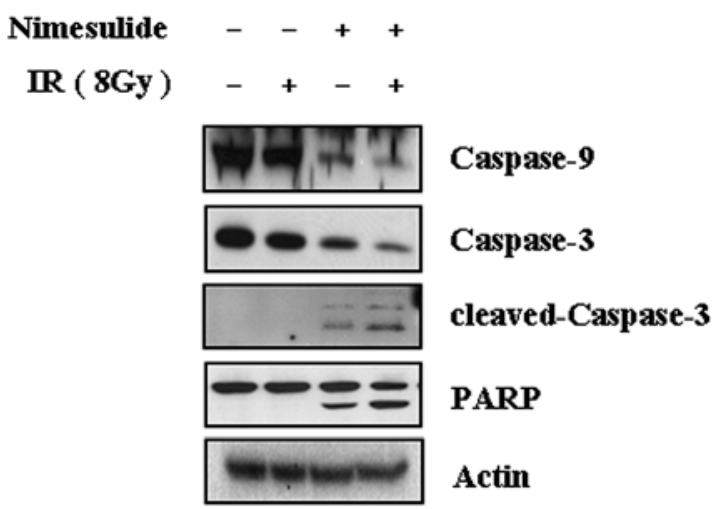

C.

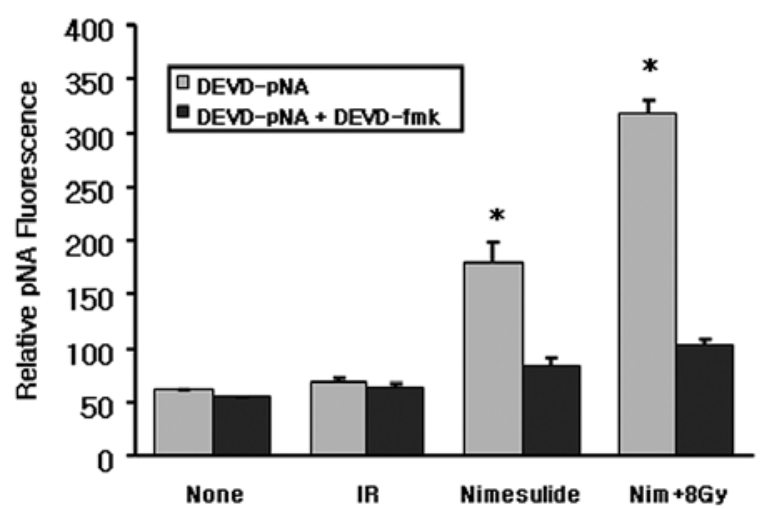

Figure 2. Pro-apoptotic effect of combined nimesulide-radiation treatment in A549 cells. At $\mathrm{t}=0$, cells were pretreated with nimesulide $(200 \mu \mathrm{M})$ for $24 \mathrm{~h}$ before treatment with radiation ( $8 \mathrm{~Gy})$, and then cultured for an additional 24 or $48 \mathrm{~h}$ ( $\mathrm{t}=48$ or $72 \mathrm{~h}$, respectively). (A) To measure apoptosis, cells were stained with propidium iodide and analyzed by flow cytometry to detect the sub-G1 cellular DNA fraction. Error bars represent the SEM of three independent experiments $\left({ }^{*} \mathrm{P}<0.05\right.$; ANOVA/Dunnett test). (B) Protein levels of caspase-9, caspase-3, and PARP were analyzed by Western blotting at $\mathrm{t}=48 \mathrm{~h}$. Blots shown are representative of three experiments. (C) Caspase-3like activity was measured at $\mathrm{t}=48 \mathrm{~h}$. The amount of pNA liberated from DEVD-pNA after a 2-h incubation at $37^{\circ} \mathrm{C}$ was determined colorimetrically. Data shown represent means \pm SEM of three independent experiments $\left({ }^{*} \mathrm{P}<0.05 ;\right.$ ANOVA/Dunnett test $)$. 
A.

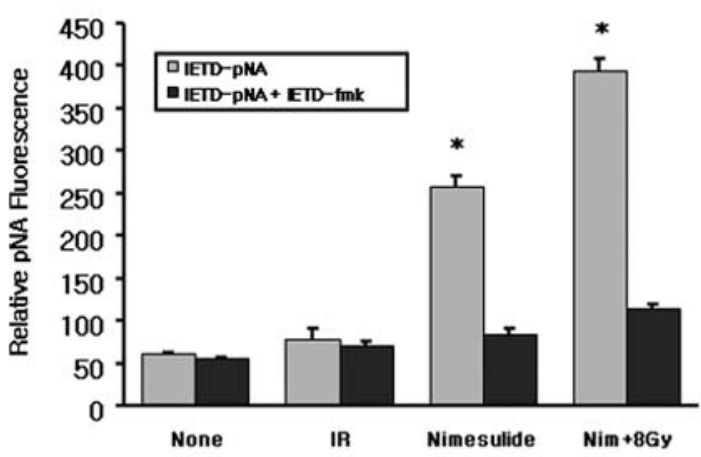

B.

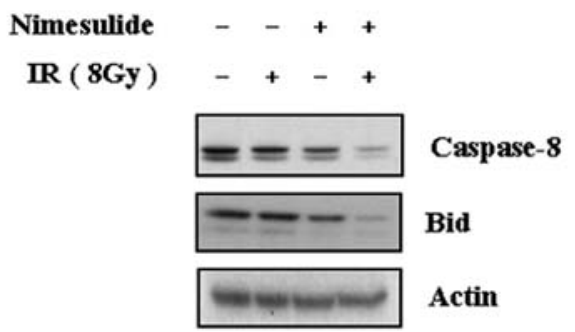

Figure 3. Activation of the caspase-8/Bid pathway in A549 cells by combined nimesulide-radiation treatment. Cells were treated with radiation alone (for $48 \mathrm{~h}$ ), nimesulide alone (for $48 \mathrm{~h}$ ), or with nimesulide pretreatment for $24 \mathrm{~h}$ followed by irradiation for $24 \mathrm{~h}$. (A) Caspase- 8 activity was monitored via the detection of pNA liberated from the IETD-pNA substrate. The increase in activity was calculated by comparing treated samples to untreated controls. All samples were measured in triplicate. Data points represent the mean \pm SEM of three independent experiments $\left({ }^{*} \mathrm{P}<0.05\right.$; ANOVA/Dunnett test). (B) Western blotting was used to analyze the expression of caspase- 8 and Bid. Blots shown are representative of three separate experiments.

nimesulide-radiation treatment of human A549 cells, we examined changes in the levels of apoptosis-related proteins. As shown in Fig. 2B, the combined treatment activated caspase-9 and caspase- 3 and increased caspase-3-mediated PARP cleavage.

We also investigated whether the combined treatment induced caspase activation by examining the enzymatic protease activity of caspase-3 using DEVD-p-nitroanilide (DEVD-pNA), a colorogenic synthetic peptide substrate for caspase-3. As shown in Fig. 2C, caspase-3 was activated more by the combined treatment than by nimesulide treatment alone or by radiation treatment alone.

Activation of the caspase-8/Bid pathway by combined nimesulide-radiation treatment. Caspase- 8 acts as an initiator caspase; its main function is to activate downstream caspases such as caspase-3, caspase-6, and caspase-7 $(21,22)$. Bid conveys apoptotic signals from caspase- 8 to the mitochondria $(9,23)$. To measure changes in caspase- 8 activity, we compared the absorbance of p-nitroanilide substrate to that of cells treated with either nimesulide alone or radiation alone and that of untreated control. Caspase- 8 activity was enhanced much more dramatically in the combination-treated samples than in the other samples (Fig. 3A).
A.

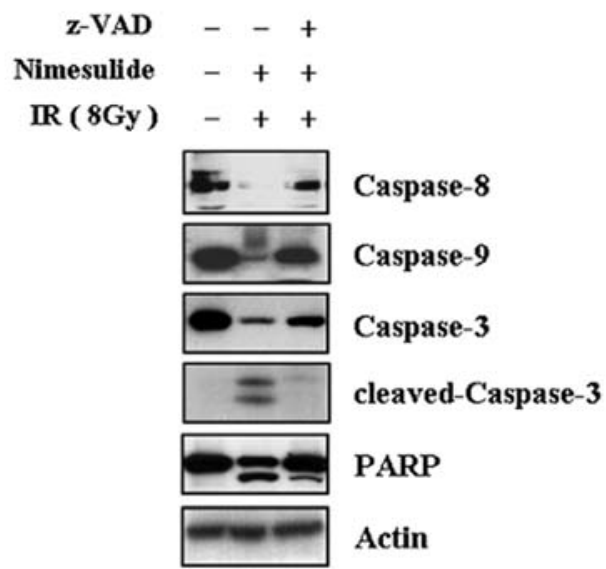

B.
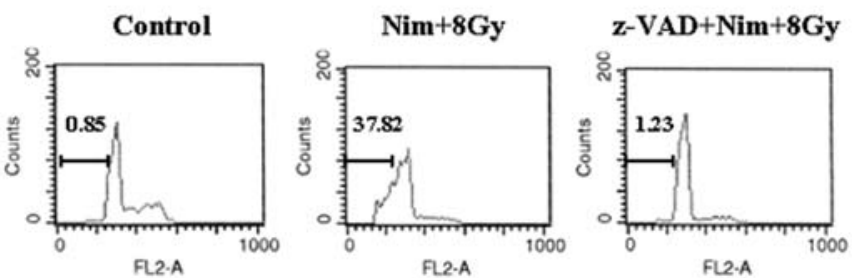

Figure 4. Inhibition of cleavage of caspase-8, caspase-9, caspase-3, and PARP, and of concomitant apoptosis by z-VAD-fmk in A549 cells treated with nimesulide and radiation. After a 1-h preincubation with $\mathrm{z}-\mathrm{VAD}$-fmk $(50 \mu \mathrm{M})$, cells were pretreated with nimesulide $(200 \mu \mathrm{M})$ for $24 \mathrm{~h}$, irradiated ( $8 \mathrm{~Gy}$ ), and then cultured for an additional $24 \mathrm{~h}$. Activation of survival signals by z-VAD-fmk was examined by Western blotting (A) and detection of the sub-G1 DNA content (B).

We also found that caspase- 8 cleavage was enhanced by the combination treatment (Fig. 3B). Because caspase- 8 activation affects the mitochondria via caspase-8-mediated cleavage of Bid, we analyzed whether the combination treatment led to the generation of truncated Bid. A549 cells treated with the combination of nimesulide and radiation exhibited a marked decrease in Bid (Fig. 3B). These results suggest that nimesulide exerts its radiosensitizing effects through caspase- 8 activation and Bid cleavage.

A pan-caspase inhibitor blocks cleavage of caspase-3, caspase-8, caspase-9, and PARP and blocks concomitant apoptosis induced by combined nimesulide-radiation treatment. Next, we determined whether nimesulide-induced radiosensitization of apoptosis was dependent on caspase activation. When A549 cells were pretreated for $1 \mathrm{~h}$ with z-VAD-fmk, a broad-spectrum caspase inhibitor, at a dose of $50 \mu \mathrm{M}$, and then exposed to nimesulide and radiation, the combination treatment-induced cleavage of caspase-3, caspase-8, caspase-9, and PARP and concomitant apoptosis were blocked (Fig. 4). These results indicate that the nimesulide sensitization of radiation-induced apoptosis depends on caspase activation.

Essential roles of caspase-3 and caspase-8 in apoptosis induced by combined nimesulide-radiation in A549 cells. 
A.
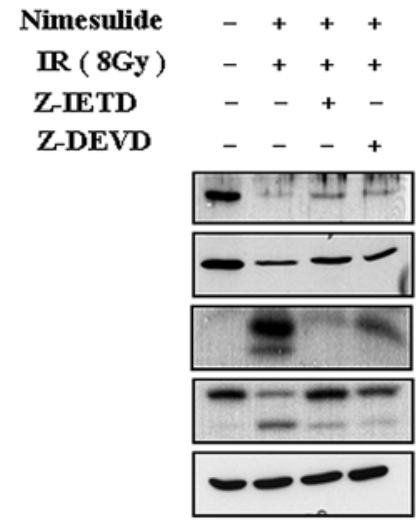

Caspase 9

Caspase 3

cleaved-Caspase 3

PARP

Actin

C.

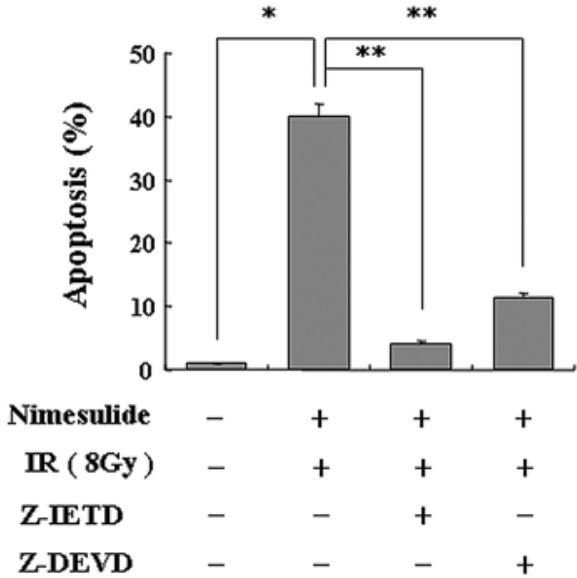

To investigate the mechanism of caspase pathway during apoptosis, A549 cells were pretreated with $50 \mu \mathrm{M}$ z-IETDfmk (a caspase-8 inhibitor) or with $50 \mu \mathrm{M} \mathrm{z}$-DEVD-fmk (a caspase- 3 inhibitor) for $1 \mathrm{~h}$ before nimesulide treatment and irradiation. The caspase- 8 inhibitor almost completely abolished the combination treatment-induced cleavage of caspase-8, Bid, caspase-9, caspase-3, and PARP (Fig. 5A and B), as well as the resulting apoptosis (Fig. 5C). The caspase-3 inhibitor suppressed caspase-3 and caspase-3mediated PARP cleavage (Fig. 5A) and the resulting apoptosis (Fig. 5C), but only partially inhibited the cleavage of caspase-8 and Bid (Fig. 5B), suggesting that caspase-8 and caspase- 3 are indispensable for the execution of apoptosis, and that caspase- 8 serves as an initial caspase in the apoptosis induced by the combined treatment of A549 cells with nimesulide and radiation.

Prolonged inhibition of tumor growth in a lung carcinoma xenograft model by combined nimesulide-radiation treatment. To evaluate the radiosensitizing effect of nimesulide in a xenograft model, BALB/c nude mice bearing A549 lung carcinomas on their rear flanks were treated with $0.5 \mathrm{mg} / \mathrm{kg}$ of intraperitoneal nimesulide $24 \mathrm{~h}$ before a single radiation dose of 8 Gy was delivered locally to the tumor. Control mice received injections of the same volume of the vehicle (10\% DMSO in PBS, pH 7.4). Tumor growth was inhibited by nimesulide alone and by radiation alone compared with the control. However, in mice treated with the combination of nimesulide and radiation, prolonged tumor growth inhibition
B.

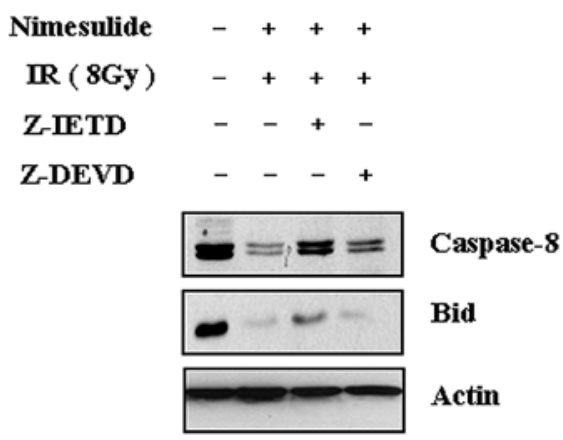

Figure 5. Inhibition of the nimesulide-induced enhancement of the radiation response by z-IETD-fmk and z-DEVD-fmk. After a 1 -h preincubation with $50 \mu \mathrm{M}$ z-IETD-fmk or z-DEVD-fmk, A549 cells were pretreated with nimesulide $(200 \mu \mathrm{M})$ for $24 \mathrm{~h}$, irradiated $(8 \mathrm{~Gy})$, and then cultured for an additional $24 \mathrm{~h}$. Activation of survival signals by z-IETD-fmk or z-DEVDfmk was examined by Western blotting (A and B) and detection of the sub-G1 DNA content $(\mathrm{C})\left({ }^{*} \mathrm{P}<0.05\right.$ vs. no treatment; ${ }^{* *} \mathrm{P}<0.05$ vs. combined nimesulide-radiation treatment; ANOVA/Dunnett test).

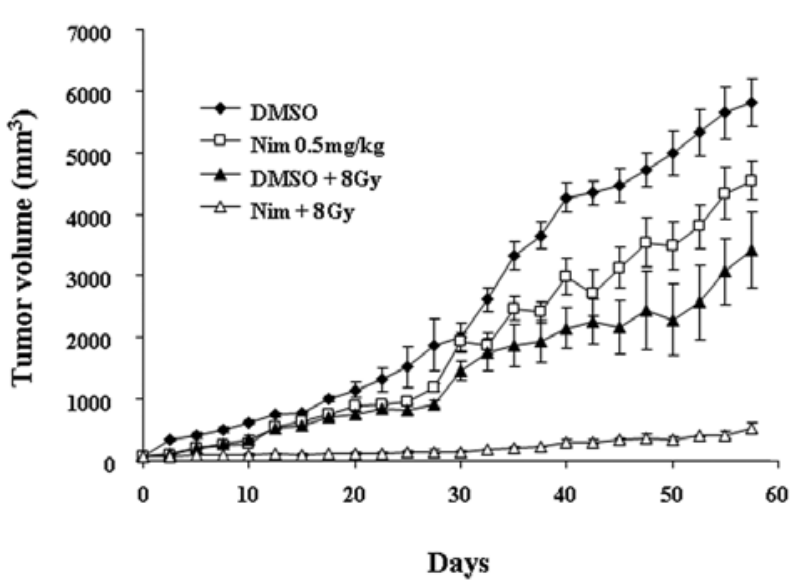

Figure 6. Effect of combined nimesulide-radiation treatment on the growth of A549 lung cancer xenografts in nude mice. Nude mice (7-weeks old) bearing subcutaneous A549 lung carcinoma xenografts $\left(70-80 \mathrm{~mm}^{3}\right)$ were pretreated with vehicle (10\% DMSO in PBS, $\mathrm{pH} 7.4)$ or nimesulide $(0.5 \mathrm{mg} /$ $\mathrm{kg}$ ) on day 0 . After $24 \mathrm{~h}, 8 \mathrm{~Gy}$ of radiation was delivered locally to the mouse xenografts using a ${ }^{60} \mathrm{Co}$ irradiator. Data shown represent the mean \pm SEM of two independent experiments using five mice per group in each experiment.

was observed (Fig. 6). The combined treatment produced significant growth inhibition compared with either treatment alone. The difference between the radiation only group and the nimesulide-radiation group reached a substantial level by day 10 . 


\section{Discussion}

There is considerable evidence that COX-2 inhibitors such as celecoxib $(19,20)$ can enhance the sensitivity of tumor cells to radiation $(1,2)$. Recently, a Phase I clinical trial showed that thoracic radiotherapy concurrent with administration of celecoxib at doses up to the maximum Food and Drug Administration-approved dose is safe in patients with nonsmall cell lung cancer, encouraging further assessment in a Phase II/III trial (24). However, although celecoxib has been reported to induce apoptosis in various tumor cells, it does not significantly induce apoptosis or radiosensitize cell killing in A549 human lung carcinoma cells (19). On the other hand, nimesulide has been reported to suppress tumor cell proliferation, but does not induce apoptosis in various tumor cells $(25,26)$. Nevertheless, in MCF-7/casp-3 breast carcinoma cells and HeLa cells, nimesulide at $100 \mu \mathrm{M}$ was found to sensitize apoptosis in response to extrinsic death pathwayinducing agents, such as TNF, CD95, and TRAIL, but not in response to intrinsic death stimuli, such as etoposide and doxorubicin (27).

In the present study, we showed that nimesulide treatment at a dose of $200 \mu \mathrm{M}$ [a dose that did not induce significant apoptosis when used alone $(<20 \%)]$ increased the radiosensitivity of A549 lung carcinoma cells when used in combination with radiotherapy. This increase was greater than that observed for combined therapy with radiation and celecoxib at a dose of $20 \mu \mathrm{M}$, the celecoxib dose at which the sublethality was identical to that of nimesulide at $200 \mu \mathrm{M}$ (data not shown). Interestingly, nimesulide treatment in combination with radiation enhanced apoptosis and radiosensitivity despite the fact that radiation induces the intrinsic apoptotic pathway. We surmise that nimesulide has drug- or cell type-specific effects on the stress-induced pathways.

The results of this study provide insight into the signaling mechanisms that underlie the induction of apoptosis in A549 cells by combined nimesulide-radiation treatment. We examined the increase in the sub-G1 cellular DNA fraction in cells exposed to the combined treatment. The results of Western blot analysis of caspase-9, caspase-3, and PARP levels and of caspase-3-like activity assays confirm that nimesulide, when used with radiation, greatly induces caspase-mediated apoptotic signals.

Activation of caspase- 8 can be mediated by several death receptors, including Fas, TNFR1, DR4, and DR5 (28). Indomethacin and sulindac sulfide induce apoptosis of Jurkat human leukemic cells by a mechanism that requires the FADD-mediated activation of a caspase-8-dependent pathway (29). Moreover, sulindac sulfide and celecoxib up-regulate DR5 expression levels in various colon and prostate cancer cell lines (30). Fas was recently reported to be involved in the p53-dependent apoptotic response to ionizing radiation in mouse testis (31) and to be up-regulated by radiation in a p53dependent fashion (32). After cleavage to its truncated form, Bid, a specific substrate for caspase- 8 , translocates from the cytosol to the mitochondria and induces mitochondrial damage $(9,23)$. Bid is cleaved prior to mitochondrial alterations, providing a molecular link between caspase- 8 activation and mitochondrial perturbation in cells in which both the receptor and the mitochondrial pathway are activated during drug treatment (33). Here, we demonstrated that combined nimesulide-radiation treatment triggers the caspase-8/Bid pathway, suggesting that the mitochondrial pathway mediates the apoptosis induced by combined nimesulide-radiation treatment.

The increase in apoptosis induced by combined nimesulideradiation treatment appears to be dependent on caspase activation; apoptosis was completely inhibited by the broadspectrum caspase inhibitor, z-VAD-fmk. In addition, caspase- 8 and caspase- 3 seem to be essential for the execution of apoptosis, since both z-IETD-fmk and z-DEVD-fmk significantly suppressed the induction of apoptosis. Apoptosis might be initiated not by mitochondria but, rather, by caspase-8, as evidenced by the observation that pretreatment with a selective caspase- 8 inhibitor restored not only caspase- 8 , but also caspase-3, and almost completely abrogated apoptosis induced by the combined treatment. However, a selective caspase-3 inhibitor did not inhibit the cleavage of caspase- 8 or Bid, indicating that caspase- 8 functions upstream of caspase- 3 .

At a clinically achievable concentration $(0.5 \mathrm{mg} / \mathrm{kg})$, nimesulide significantly delayed tumor growth in a nude mouse xenograft model, substantiating the possibility of a clinical application for nimesulide in anticancer radiotherapy. Of course, we did not exclude the possibility that another mechanism, such as the inhibition of angiogenesis, might be responsible for the antitumor effect or increased radiosensitivity in the xenograft model. Nonetheless, we expect that the highly selective COX-2 inhibitor, nimesulide, will lead to more efficacious radiotherapy for cancer patients when used as a radiotherapy adjunct.

In our experiments, radiosensitization of cell death (clonogenicity and apoptosis) required nimesulide at a concentration of $200 \mu \mathrm{M}$, a much higher dose than that sufficient to inhibit PGE2 production $(<10 \mu \mathrm{M})(25,26)$. Our data obtained in vitro suggest that a higher dose is required to enhance the radiation response than to exert anti-inflammatory effects (data not shown).

Taken together, our results demonstrate that nimesulide increases the radiosensitivity of tumor cells via apoptosis in vitro and in vivo, with the activation of caspase- 8 and caspase-3. In addition, because there is no correlation between COX-2 expression and the radiosensitizing effect of nimesulide, a selective COX-2 inhibitor, our findings indicate that nimesulide is a potential therapeutic adjunct for increasing the efficiency of various anticancer agents and antitumor radiation therapy.

\section{Acknowledgments}

This study was supported by a grant of the National Nuclear R\&D Program of the Ministry of Education, Science and Technology (MEST) of the Republic of Korea.

\section{References}

1. Palayoor ST, Bump EA, Calderwood SK, Bartol S and Coleman $\mathrm{CN}$ : Combined antitumor effect of radiation and ibuprofen in human prostate carcinoma cells. Clin Cancer Res 4: 763-771, 1998.

2. Furuta Y, Hunter N, Barkley T Jr, Hall E and Milas L: Increase in radioresponse of murine tumors by treatment with indomethacin. Cancer Res 48: 3008-3013, 1988. 
3. Putcha GV, Harris CA, Moulder KL, Easton RM, Thompson CB and Johnson EM Jr: Intrinsic and extrinsic pathway signaling during neuronal apoptosis: lessons from the analysis of mutant mice. J Cell Biol 157: 441-453, 2002.

4. Liu X, Kim CN, Yang J, Jemmerson R and Wang X: Induction of apoptotic program in cell-free extracts: requirement for dATP and cytochrome c. Cell 86: 147-157, 1996.

5. Du C, Fang M, Li Y, Li L and Wang X: Smac, a mitochondrial protein that promotes cytochrome c-dependent caspase activation by eliminating IAP inhibition. Cell 102: 33-42, 2000.

6. Ozören N and El-Deiry WS: Cell surface death receptor signaling in normal and cancer cells. Semin Cancer Biol 13: $135-147,2003$

7. Yin XM and Ding WX: Death receptor activation-induced hepatocyte apoptosis and liver injury. Curr Mol Med 3: 491-508, 2003.

8. Chen $\mathrm{M}$ and Wang $\mathrm{J}$ : Initiator caspases in apoptosis signaling pathways. Apoptosis 7: 313-319, 2002.

9. Henshall DC, Bonislawski DP, Skradski SL, Lan JQ, Meller R and Simon RP: Cleavage of Bid may amplify caspase-8-induced neuronal death following focally evoked limbic seizures. Neurobiol Dis 8: 568-580, 2001.

10. Davis R and Brogden RN: Nimesulide. An update of its pharmacodynamic and pharmacokinetic properties, and therapeutic efficacy. Drugs 48: 431-454, 1994.

11. Singla AK, Chawla M and Singh A: Nimesulide: some pharmaceutical and pharmacological aspects-an update. J Pharm Pharmacol 52: 467-486, 2000.

12. Maltese A, Maugeri F and Bucolo C: Rapid determination of nimesulide in rabbit aqueous humor by liquid chromatography. J Chromatogr B Analyt Technol Biomed Life Sci 804: 441-443, 2004.

13. Okajima E, Denda A, Ozono S, Takahama M, Akai H, Sasaki Y, Kitayama W, Wakabayashi K and Konishi Y: Chemopreventive effects of nimesulide, a selective cyclooxygenase- 2 inhibitor, on the development of rat urinary bladder carcinomas initiated by N-butyl-N-(4-hydroxybutyl) nitrosamine. Cancer Res 58: 3028-3031, 1998.

14. Fukutake M, Nakatsugi S, Isoi T, Takahashi M, Ohta T, Mamiya S, Taniguchi Y, Sato H, Fukuda K, Sugimura T and Wakabayashi K: Suppressive effects of nimesulide, a selective inhibitor of cyclooxygenase-2, on azoxymethane-induced colon carcinogenesis in mice. Carcinogenesis 19: 1939-1942, 1998.

15. Nakatsugi S, Ohta T, Kawamori T, Mutoh M, Tanigawa T, Watanabe K, Sugie S, Sugimura T and Wakabayashi K: Chemoprevention by nimesulide, a selective cyclooxygenase- 2 inhibitor, of 2-amino-1-methyl-6-phenylimidazo[4,5-b]pyridine (PhIP)-induced mammary gland carcinogenesis in rats. Jpn J Cancer Res 91: 886-892, 2000.

16. Shiotani H, Denda A, Yamamoto K, Kitayama W, Endoh T, Sasaki Y, Tsutsumi N, Sugimura M and Konishi Y: Increased expression of cyclooxygenase-2 protein in 4-nitroquinoline-1oxide-induced rat tongue carcinomas and chemopreventive efficacy of a specific inhibitor, nimesulide. Cancer Res 61: 1451-1456, 2001.

17. Denda A, Kitayama W, Murata A, Kishida H, Sasaki Y, Kusuoka O, Tsujiuchi T, Tsutsumi M, Nakae D, Takagi H and Konishi Y: Increased expression of cyclooxygenase-2 protein during rat hepatocarcinogenesis caused by a cholinedeficient, L-amino acid-defined diet and chemopreventive efficacy of a specific inhibitor, nimesulide. Carcinogenesis 23: $245-256,2002$
18. Grimes KR, Warren GW, Fang F, Xu Y and St Clair WH: Cyclooxygenase-2 inhibitor, nimesulide, improves radiation treatment against non-small cell lung cancer both in vitro and in vivo. Oncol Rep 16: 771-776, 2006.

19. Liu W, Chen Y, Wang W, Keng P, Finkelstein J, Hu D, Liang L, Guo M, Fenton B, Okunieff P and Ding I: Combination of radiation and Celebrex (celecoxib) reduce mammary and lung tumor growth. Am J Clin Oncol 26: S103-S109, 2003.

20. Nakata E, Mason KA, Hunter N, Husain A, Raju U, Liao Z, Ang KK and Milas L: Potentiation of tumor response to radiation or chemoradiation by selective cyclooxygenase- 2 enzyme inhibitors. Int J Radiat Oncol Biol Phys 58: 369-375, 2004.

21. Muzio M, Chinnaiyan AM, Kischkel FC, O'Rourke K, Shevchenko A, Ni J, Scaffidi C, Bretz JD, Zhang M, Gentz R, Mann M, Krammer PH, Peter ME and Dixit VM: FLICE, a novel FADD-homologous ICE/CED-3-like protease, is recruited to the CD95 (Fas/APO-1) death-inducing signaling complex. Cell 85: 817-827, 1996.

22. Mehmet H: Caspases find a new place to hide. Nature 403: 29-30, 2000.

23. Li H, Zhu H, Xu CJ and Yuan J: Cleavage of BID by caspase 8 mediates the mitochondrial damage in the Fas pathway of apoptosis. Cell 94: 491-501, 1998.

24. Liao Z, Komaki R, Milas L, Yuan C, Kies M, Chang JY, Jeter M, Guerrero T, Blumenschien G, Smith CM, Fossella F, Brown B and Cox JD: A phase I clinical trial of thoracic radiotherapy and concurrent celecoxib for patients with unfavorable performance status inoperable/unresectable non-small cell lung cancer. Clin Cancer Res 11: 3342-3348, 2005.

25. Yamazaki R, Kusunoki N, Matsuzaki T, Hashimoto S and Kawai S: Selective cyclooxygenase-2 inhibitors show a differential ability to inhibit proliferation and induce apoptosis of colon adenocarcinoma cells. FEBS Lett 531: 278-284, 2002.

26. Kusunoki N, Yamazaki R and Kawai S: Induction of apoptosis in rheumatoid synovial fibroblasts by celecoxib, but not by other selective cyclooxygenase 2 inhibitors. Arthritis Rheum 46: 3159-3167, 2002.

27. Totzke G, Schulze-Osthoff K and Jänicke RU: Cyclooxygenase-2 (COX-2) inhibitors sensitize tumor cells specifically to death receptor-induced apoptosis independently of COX-2 inhibition. Oncogene 22: 8021-8030, 2003.

28. Thorburn A: Death receptor-induced cell killing. Cell Signal 16: 139-144, 2004.

29. Han Z, Pantazis P, Wyche JH, Kouttab N, Kidd VJ and Hendrickson EA: A Fas-associated death domain proteindependent mechanism mediates the apoptotic action of nonsteroidal anti-inflammatory drugs in the human leukemic Jurkat cell line. J Biol Chem 276: 38748-38754, 2001.

30. Huang Y, He Q, Hillman MJ, Rong R and Sheikh MS: Sulindac sulfide-induced apoptosis involves death receptor 5 and the caspase 8-dependent pathway in human colon and prostate cancer cells. Cancer Res 61: 6918-6924, 2001.

31. Embree-Ku M, Venturini D and Boekelheide K: Fas is involved in the p53-dependent apoptotic response to ionizing radiation in mouse testis. Biol Reprod 66: 1456-1461, 2002.

32. Sheard MA, Uldrijan S and Vojtesek B: Role of p53 in regulating constitutive and X-radiation-inducible CD95 expression and function in carcinoma cells. Cancer Res 63: 7176-7184, 2003.

33. Fulda S, Meyer E, Friesen C, Susin SA, Kroemer G and Debatin KM: Cell type specific involvement of death receptor and mitochondrial pathways in drug-induced apoptosis. Oncogene 20: 1063-1075, 2001. 